\title{
EFFECT OF GRAPHENE ON THE PROPERTIES OF EPOXIDIZED-PALM-OIL PLASTICIZED POLY(LACTIC ACID) BIOPOLYMER NANOCOMPOSITES
}

\author{
VPLIV GRAFENA NA LASTNOSTI PLA BIOPOLIMERNIH \\ NANOKOMPOZITOV PLASTIFICIRANIH Z EPOKSIDIZIRANIM \\ PALMINIM OLJEM
}

\author{
Buncha Suksut $^{1 *}$, Sorawit Duangsripat ${ }^{2}$ \\ ${ }^{1}$ Faculty of Engineering and Technology, King Mongkut's University of Technology North Bangkok, \\ Rayong Campus, Rayong 21120, Thailand \\ ${ }^{2}$ Haydale Technologies (Thailand) Company Limited, D510-D515, NIC2 Building 1, Tower D, 141 Moo 9, Thailand Science Park, \\ Phaholyothin Rd., Khlong Luang, Pathumthani 12120, Thailand
}

Prejem rokopisa - received: 2019-07-03; sprejem za objavo - accepted for publication: 2019-12-12

doi:10.17222/mit.2019.140

\begin{abstract}
This work focused on an analysis of the relationship between the morphology and properties of epoxidized palm oil (EPO) plasticized poly(lactic acid) (PLA) filled with graphene (GP). Differential scanning calorimetry results showed that GPs can act as nucleating agents for PLA, which decreased the cold crystallization temperature and increased the crystallinity. This nucleating effect of the GP was less effective in the PLA/EPO blends, due to its preferred dispersion in the EPO phase. By polarized light microscopy observation, the spherulite size of the PLA decreased with the presence of GP in the PLA/EPO blends, while the EPO provided the larger spherulite size as compared to neat PLA. Nevertheless, the increase in crystallinity, especially at high GP loadings, helped to retain the mechanical properties of the plasticized PLA.

Keywords: graphene, polylactic acid, nanocomposites, crystallization

V tem prispevku avtorji opisujejo raziskavo, ki se je osredotočala na analizo povezave med morfologijo in lastnostmi z epoksidiziranim palminim oljem (EPO) plastificirane polilaktične kisline (PLA), polnjene z grafenom (GP). Rezultati diferencialne vrstične kalorimetrije (DSC) so pokazali, da GP lahko deluje kot sredstvo za tvorbo jeder (nukleacijo) PLA, kar zmanjšuje hladno kristalizacijo in povečuje kristaliničnost. Ta nukleacijski učinek GP je manj učinkovit v PLA/EPO-mešanicah, zaradi njegove prednostne disperzije v EPO-fazi. Dodatna opazovanja v optičnem polarizacijskem mikroskopu so pokazala, da se velikost PLA-sferulita zmanjšuje s prisotnostjo GP v PLA/EPO-mešanicah, medtem ko EPO zagotavlja večjo velikost sferulita v primerjavi s čistim PLA. Ceprav GP povečuje kristaliničnost, še posebej pri njegovih večjih deležih, pomaga ohranjati mehanske lastnosti plastificiranega PLA.
\end{abstract}

Ključne besede: grafen, polilaktična kislina, nanokompoziti, kristalizacija

\section{INTRODUCTION}

Biodegradable polymer is of great interest as an environmentally friendly material. Poly(lactic acid), PLA, is the most widely used and fastest-growing class of biodegradable polymer, which exhibits environmentally friendly, good clarity, high strength and moderate barrier properties. However, the problems of PLA are the mechanical brittleness and slow crystallization rate, inducing more difficult to control the processing. The improvement of the mechanical brittleness can be done by adding:

1) the filler particles as impact modifier,

2) polymer component such as thermoplastic or rubber material in PLA matrix and

3) plasticizer. $^{1-5}$

To retain biodegradability property of PLA, many studies have focused on blending PLA with other bio-

*Corresponding author's e-mail:

buncha.s@eat.kmutnb.ac.th (Buncha Suksut) degradable materials deriving from renewable plants. Epoxidized vegetable-oil-based plasticizer, such as epoxidized soybean oil (ESO) and epoxidized palm oil (EPO), is employed as a feasible alternative..$^{6,7}$

The increase in flexibility of plasticized PLA is always accompanied by a drop in strength and stiffness. ${ }^{8}$ One of the most feasible approaches to balance the performance of polymer is the reinforcing of nanoparticles into the polymer matrix, which exhibits an enormous surface area, being larger by several orders of magnitude. These nanofillers included clay, nanocellulose and graphene (GP). ${ }^{8-12}$ According to Cheing et al. the addition of a small amount of graphene nanoplatelet $(\mathrm{xGnP})$ (up to $0.3 \mathrm{w} / \%$ ) improves the tensile properties of PLA/EPO ${ }^{8}$ The further addition of $\mathrm{xGnP}$ provides a decrease of stiffness, strength and flexibility. Sriprachuabwong et al. attributes the highest elongation at the break of PLA/EPO at an optimal GP loading of $0.6 w / \% 13$ However, both the stiffness and strength decreases continually with increasing GP loading. The same effect was observed for a PLA/clove essential oil (CLO) blend 
with the addition of graphene oxide (GO) nanosheets. ${ }^{12}$ Besides the reinforcement effect, the presence of nanofiller is considered to change the morphological structures, thus the final properties of products. Therefore, the main objective of this work is to focus on the influence of GP on the PLA morphology as well as on the relationship between the resulting morphology and properties of composites.

\section{EXPERIMENTAL PART}

\subsection{Materials}

Commercial poly(lactic acid) (PLA LX175, Corbion Purac) was used as a matrix in the present work. The melt flow and the density of this product are $6 \mathrm{~g} / 10 \mathrm{~min}$ $\left(210{ }^{\circ} \mathrm{C} / 2.16 \mathrm{~kg}\right.$ ) and $1.24 \mathrm{~g} / \mathrm{cm}^{3}$, respectively. The PLA was dried at $60{ }^{\circ} \mathrm{C}$ for $12 \mathrm{~h}$ in an oven before use. Epoxidized palm oil (EPO) (Multi Ple Plus Company Limited) was used as a plasticizer. Graphene (GP) synthesized by electrolytic exfoliation under the condition described in ${ }^{13}$ was supported by Haydale Technologies (Thailand) Company Limited.

\subsection{Preparation of PLA/EPO/GP nanocomposites}

In order to obtain a homogeneous nanoparticle dispersion, a masterbatch preparation was adopted for the compounding of nanocomposites. PLA/EPO blends with and without $0.3 w / \%$ of GP were first prepared using an internal mixer (MX500, Chareontut) at a mixing temperature of $190{ }^{\circ} \mathrm{C}$ and a rotor speed of $60 \mathrm{~min}^{-1}$ for $20 \mathrm{~min}$. The PLA/EPO composition at a weight ratio of 97:3 was used. This composition was reported to yield the optimal mechanical properties. ${ }^{14}$ The masterbatches were cooled in air for $30 \mathrm{~min}$ before grinding with a mechanical grinder. Because of the limitation of the yielding of the GP from electrolytic exfoliation preparation and the requirement of transparent samples, the maximum concentration of GP in this work was $0.2 w / \%$. In the second step, the masterbatches were then diluted to the designed GP concentration varied from 0.02 to $0.20 w / \%$ by a co-rotating twin-screw extruder (CTE-D22L32, Chareontut) at a screw speed of $60 \mathrm{~min}^{-1}$. The temperature was set from $190{ }^{\circ} \mathrm{C}$ near the hopper to $200{ }^{\circ} \mathrm{C}$ at the die. The diameter of the screw was $22 \mathrm{~mm}$ and the L/D (length/diameter) ratio was 32.

After extrusion, the neat PLA and its nanocomposites were injection molded (100ECS, JSW) to tensile test samples according to ASTM D638 type I and impact test samples according to ASTM D256. The temperatures were set from $180{ }^{\circ} \mathrm{C}$ near the hopper to $210^{\circ} \mathrm{C}$ at the nozzle. A mold temperature of $40{ }^{\circ} \mathrm{C}$ and an injection rate of $10 \mathrm{ccm} / \mathrm{s}$ were used.

\subsection{Characterization of PLA/EPO/GP nanocomposites}

The structure of the GP synthesized by electrolytic exfoliation was characterized by Raman spectroscopy
(Ram II, Bruker). The morphology of the GP and fractured surface of PLA and its nanocomposites after the impact test were examined with a scanning electron microscope (SEM, model JSM 6400, JEOL) at room temperature. An acceleration voltage of $20 \mathrm{kV}$ was used to collect the SEM images for the sample. The fracture surface sample was coated with gold for $3 \mathrm{~min}$ before analysis.

In order to reveal the dispersion of graphene in PLA/EPO/GP nanocomposites, a microtomed thin section of $10 \mu \mathrm{m}$ cut from the injection-molded plate was applied onto a glass slide and covered by a cover slip. The sample was then analyzed with a transmitted-light microscope (DM2700M, Leica).

The spherulitic structure of PLA, as obtained from the isothermal crystallization, was observed under a polarized optical microscope (DM2700M, Leica) equipped with a heating stage (LTS420, LINKAM). The thin section of $10 \mu \mathrm{m}$ was heated to $210{ }^{\circ} \mathrm{C}$ on the heating stage and kept for 5 minutes at $210{ }^{\circ} \mathrm{C}$ to erase the previous processing history. It was then cooled to $120{ }^{\circ} \mathrm{C}$, and held constant until the completion of the crystallization.

The thermal properties were determined using a differential scanning calorimeter (DSC, Q200, TA instruments) equipped with a Refrigerated Cooling Systems 90 (RCS90). Indium was used as a reference material to calibrate both the temperature scale and the melting enthalpy before the samples were measured in alternate runs and the baseline was subtracted. The calorimeter was purged with nitrogen gas throughout the measurement. The weight of each sample, between 5 and $10 \mathrm{mg}$, was placed in an aluminium pan and the pan was then completely sealed with an aluminium lid.

The sample was initially heated from $0{ }^{\circ} \mathrm{C}$ to $210{ }^{\circ} \mathrm{C}$ at the rate of $20{ }^{\circ} \mathrm{C} / \mathrm{min}$ and held for $5 \mathrm{~min}$ at $210{ }^{\circ} \mathrm{C}$ to ensure the complete melting of the previous crystals and to erase their process history. Subsequently, the sample was cooled to $0{ }^{\circ} \mathrm{C}$ at the rate of $10{ }^{\circ} \mathrm{C} / \mathrm{min}$. The glasstransition temperature $\left(T_{\mathrm{g}}\right)$, melting temperature $\left(T_{\mathrm{m}}\right)$, peak crystallization temperature during heating $\left(T_{\mathrm{cc}}\right)$ and degree of crystallinity $\left(\% X_{\mathrm{c}}\right)$ from the heat of fusion were determined.

Tensile tests were conducted using a universal testing machine (Model 25 ST, Tinius Olsen) with a load cell of $5 \mathrm{kN}$ and a crosshead speed of $5 \mathrm{~mm} / \mathrm{min}$ at $25{ }^{\circ} \mathrm{C}$. A minimum of five specimens were used for each composition. The measurements of elastic modulus, stress at break and elongation at break were recorded. All the impact test samples were notched using a V-notch sampling machine (GT-7016-A2, Gotech Testing Machienes INC.) with a notch angle of $45^{\circ}$ having a radius of $0.25 \mathrm{~mm}$ and a depth of $2.54 \mathrm{~mm}$. The depth of the specimens after being notched was $10.20 \pm 0.05 \mathrm{~mm}$. A notched Izod impact test was performed according to ASTM 256 using an impact testing machine (IT 504, Tinius Olsen). The pendulum energy of $5.64 \mathrm{~J}$ was used at $25{ }^{\circ} \mathrm{C}$. A 
minimum of five specimens was tested for each composition.

\section{RESULTS AND DISCUSSION}

Figure 1 shows the corresponding Raman spectra of GP used in this research and typical graphite powder. It can be seen that the Raman spectra of both the GP and the graphite contain $\mathrm{D}, \mathrm{G}$ and $2 \mathrm{D}$ bands, as the major peaks at around $1356 \mathrm{~cm}^{-1}, 1587 \mathrm{~cm}^{-1}$ and $\approx 2700 \mathrm{~cm}^{-1}$, respectively. A sharp $\mathrm{G}$ band is an in-plane vibrational mode that involves $\mathrm{sp}^{2}$ hybridized carbon atoms that comprise the graphene sheet. The D band represents the disorder or the defect band and is generally weak in graphite. The 2D band (the second-order D band) is the result of a two phonon lattice vibration process and is always a strong band in the graphene..$^{15,16}$ Furthermore, the $\mathrm{G}$ band is stronger than the $2 \mathrm{D}$ band in the spectrum of graphene, a multilayer structure. ${ }^{17}$ This confirms that the electrolytic exfoliation method provides graphene sheets with multilayers of $\mathrm{sp}^{2}$-bonded carbon.

Representative SEM images of GP powder are displayed in Figure 2 where the GP particles were agglomerated after drying. These SEM images also reveal the thickness of the GP plate in the size range $30-100 \mathrm{~nm}$. This confirms that the GPs used in this research are on the nanoscale.

Figure 3 shows images of PLA/EPO with and without GP samples. These optical images show the microdispersion of the GP in the composites. It can be seen that there are some visible agglomerates with a size less than $1 \mu \mathrm{m}$. However, these small agglomerates are uniformly distributed and homogeneously dispersed in the PLA/EPO blends.

In order to clarify the influence of the GP nanoparticles on the crystallization of the nanocomposites, DSC measurements of neat PLA, PLA/GP and PLA/EPO/GP nanocomposites were performed. The DSC second heating thermograms of the selected samples are pre-

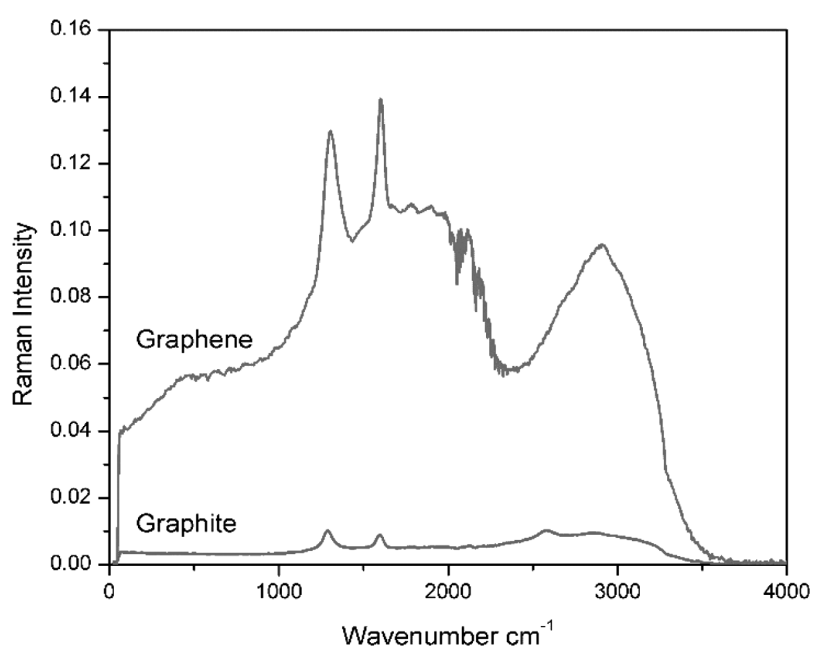

Figure 1: Raman spectrum of electrolytic exfoliation graphene
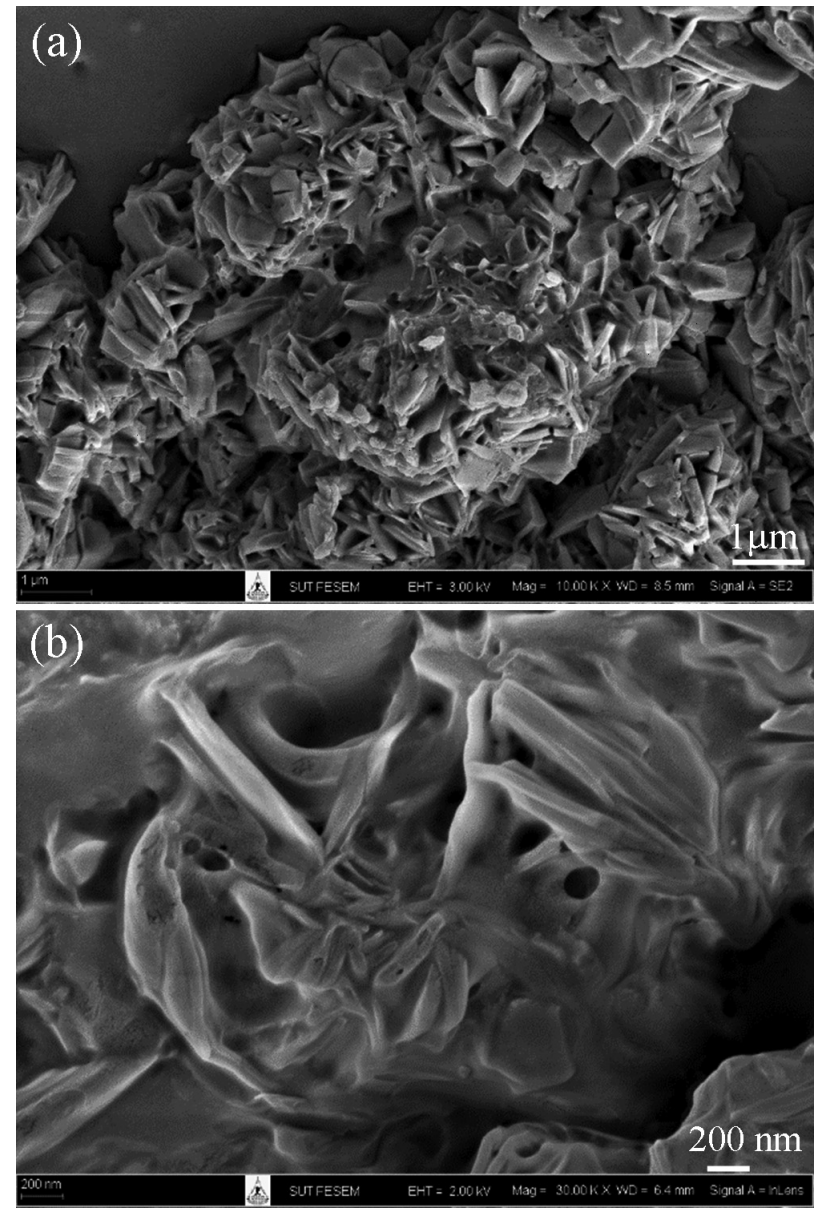

Figure 2: SEM micrographs of electrolytic exfoliated graphene powder at: a) $10000 \times$ and b) $30000 \times$

sented in Figure 4. $T_{\mathrm{g}}, T_{\mathrm{cc}}$ (determined at the peak of the exothermic area), $T_{\mathrm{m}}$ (determined at the peak of the endothermic melting area) and $\Delta \mathrm{H}_{\mathrm{m}}$ (the measured heat of fusion) are observed. All results derived from the second heating thermograms are listed in Table 1. It can

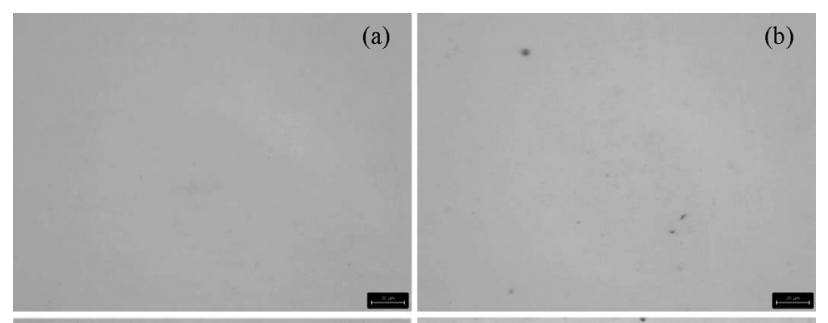

(c)

(d)

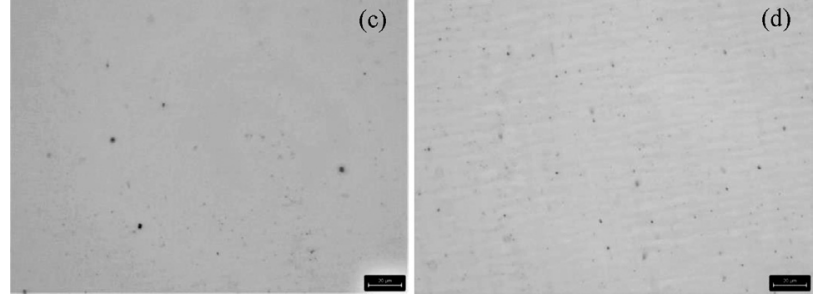

Figure 3: Representative transmitted-light images of: a) PLA/EPO, b) $\mathrm{PLA} / \mathrm{EPO} / \mathrm{GP} 0.02$, c) $\mathrm{PLA} / \mathrm{EPO} / \mathrm{GPO} 0.1$ and d) $\mathrm{PLA} / \mathrm{EPO} / \mathrm{GP} 0.2$, scalebar is $20 \mu \mathrm{m}$ 


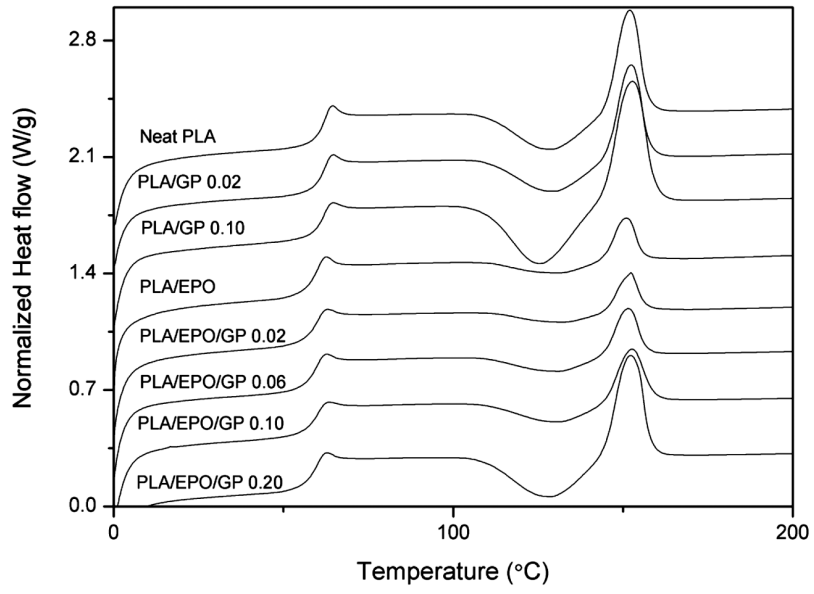

Figure 4: DSC second heating thermograms of neat PLA and PLA/EPO blends with and without GP

be seen that, a single $T_{\mathrm{g}}$ peak appeared at around $60-62{ }^{\circ} \mathrm{C}$ for all materials. This small hysteresis peak associates with physical relaxation of the molecular chain. ${ }^{18}$ As shown, the $T_{\mathrm{g}}$ slightly decreases with the presence of EPO (about $2{ }^{\circ} \mathrm{C}$ ) as compared to neat PLA. This indicates that EPO is partially miscible with PLA, increasing the chain mobility. This has been reported that the carboxyl end groups of thermoplastic polyester are miscible with epoxy resins during high-temperature mixing. ${ }^{6,19}$ In contrast, such a reduction in $T_{\mathrm{g}}$ is not observed for the PLA/GP and PLA/EPO/GP nanocomposites, indicating that GP nanoparticles have no impact on the $T_{\mathrm{g}}$ of the PLA matrix. Similar to the $T_{\mathrm{g}}$, the incorporation of GP does not significantly change the $T_{\mathrm{m}}$ of the PLA for both PLA/GP and PLA/EPO/GP.

In the present work, the PLA does not crystallize during cooling for all the materials (not shown here). The crystallization of all the samples occurs during second heating (cold crystallization). It is known that lower $T_{\mathrm{cc}}$ initiates faster crystallization. The exothermic peak of cold crystallization of neat PLA is found at $129.0{ }^{\circ} \mathrm{C}$. The incorporation of $0.10 \mathrm{w} / \%$ of GP shifts approximately $4{ }^{\circ} \mathrm{C}$ to lower temperatures (the $T_{\text {cc }}$ decreases from $129.0 \mathrm{C}$ to $125.4{ }^{\circ} \mathrm{C}$ ), implying faster crystallization. The results suggest that the GP nanoparticle act as nucleating agents for the PLA. In the heterogeneous nucleation, the nucleating agent helps lower the free-energy barrier, thus favoring faster nucleation. ${ }^{20}$ In the case of the incorporation of EPO, the DSC thermogram of PLA/EPO shows a very weak and broad exothermic peak appearing at the temperature of 131.0 ${ }^{\circ} \mathrm{C}$, which is higher than that of neat PLA. This implies that EPO retards the ability for the cold crystallization of PLA. The retarding effect of EPO still affects the PLA crystallization in PLA/EPO/GP0.02 and PLA/EPO/GP0.1. Nonetheless, the DSC thermogram of PLA/EPO/GP0.2 becomes a sharper and narrower exothermic peak in comparison with PLA/EPO. The $\mathrm{T}_{\mathrm{cc}}$ of PLA/EPO/GP0.2 is lower than that of PLA/EPO, but it is higher than that of PLA/GP0.1. This could be the result of the competition between the nucleation effect of the GP and retarding the effect of EPO. This finding
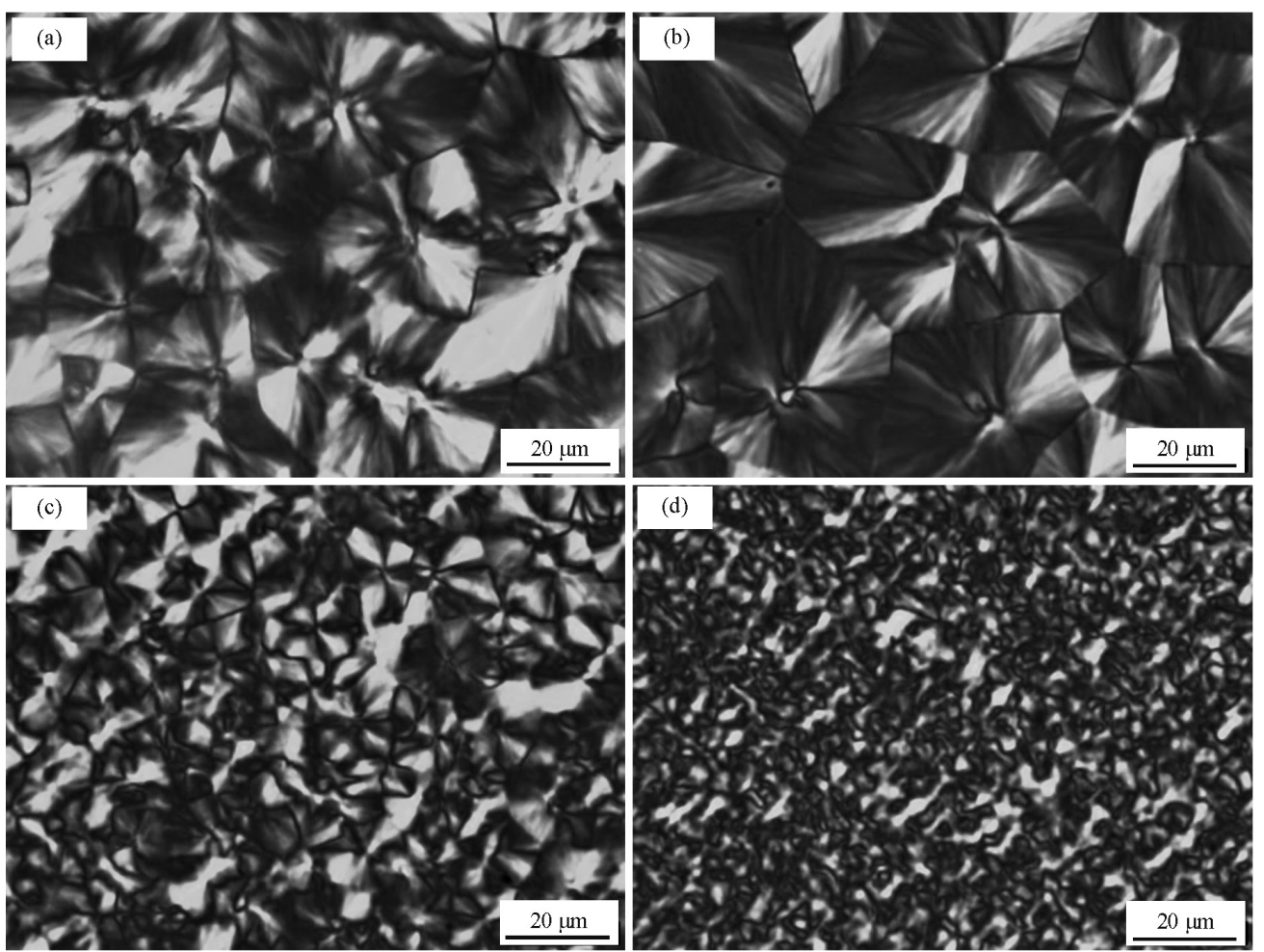

Figure 5: Polarized optical micrographs of PLA spherulites after isothermal crystallization at $120{ }^{\circ} \mathrm{C}$ in: a) neat PLA, b) PLA/EPO, c) PLA/EPO/GP0.1 and d) PLA/EPO/GP0.2 
deduces that the nucleating effect induced by the GP nanoparticles dominates over the retarding effect of the EPO only at high GP loadings $(0.20 w / \%)$.

Table 1: DSC second heating results of PLA and PLA/EPO blend with and without GP

\begin{tabular}{|c|c|c|c|c|}
\hline Samples & $T_{\mathrm{g}},{ }^{\circ} \mathrm{C}$ & $T_{\mathrm{cc}}{ }^{\circ} \mathrm{C}$ & $T_{\mathrm{m}},{ }^{\circ} \mathrm{C}$ & $\Delta \mathrm{H}_{\mathrm{m}}, \mathrm{J} / \mathrm{g}$ \\
\hline PLA & 62.2 & 129.0 & 152.1 & 14.3 \\
\hline PLA/GP0.02 & 62.3 & 130.3 & 152.4 & 13.1 \\
\hline PLA/GP0.10 & 62.0 & 125.4 & 152.9 & 21.7 \\
\hline PLA/EPO & 59.9 & 131.0 & 150.9 & 5.0 \\
\hline PLA/EPO/GP 0.02 & 59.9 & 133.0 & 152.2 & 4.4 \\
\hline PLA/EPO/GP 0.04 & 60.1 & 131.2 & 152.0 & 5.8 \\
\hline PLA/EPO/GP 0.06 & 59.8 & 130.9 & 151.4 & 6.5 \\
\hline PLA/EPO/GP 0.08 & 60.4 & 130.7 & 152.2 & 8.6 \\
\hline PLA/EPO/GP 0.10 & 60.4 & 131.0 & 152.5 & 8.1 \\
\hline PLA/EPO/GP 0.20 & 60.0 & 128.4 & 152.2 & 16.9 \\
\hline
\end{tabular}

A significant increase of the heat of fusion values of the PLA is observed with an addition of $0.10 w / \%$ of GP, as compared with the neat PLA, which had a $\Delta H_{\mathrm{m}}$, of $14.3 \mathrm{~J} / \mathrm{g}$. It is well known that a higher heat of fusion corresponds to a higher degree of crystallinity. However, a huge depression of the heat of fusion is observed with the addition of EPO. The results are in good agreement with the previous report of F. Ali. ${ }^{6}$ In PLA/EPO blends, the heat of fusion slightly increases with an increasing of the GP content up to $0.10 w / \%$ of GP and reached the maximum value at the GP content of $0.20 w / \%$, which is
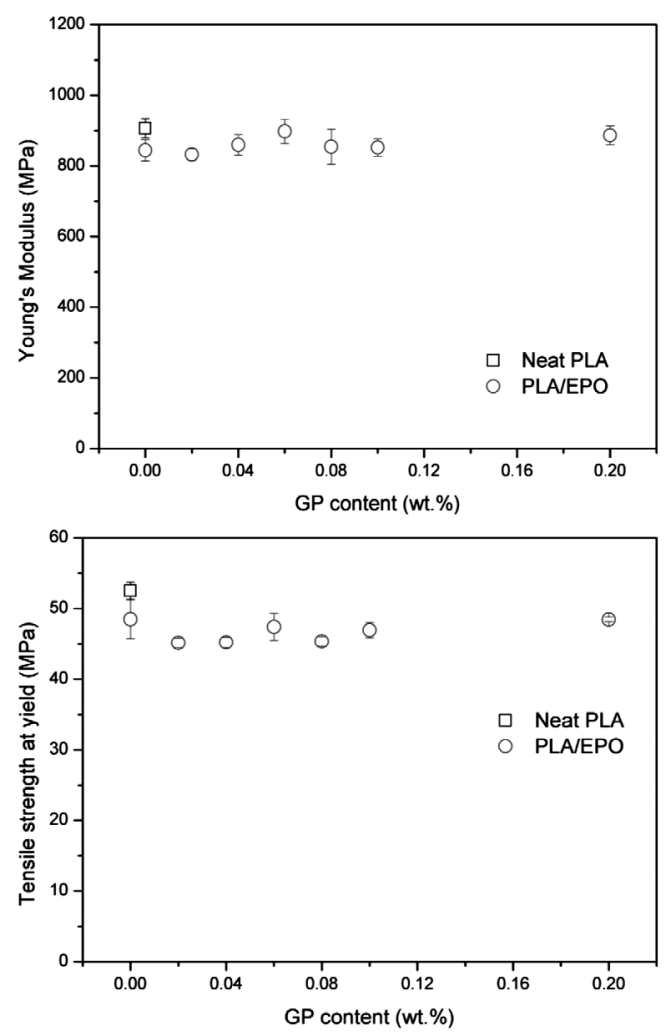

Figure 6: Young's modulus (left) and tensile strength at yield (right) of neat PLA and PLA/ESO blends with and without GP about three times greater than that of the PLA/EPO. Thus it is deduced that the GP can be considered as the most effective nucleating agent for neat PLA, but it may be less effective in PLA/EPO. It could be though that the GP preferentially dispersed in the EPO phase instead of the PLA, leading to less nucleation ability for the PLA. The nucleation effect of the GP can be confirmed by an analysis of the spherulitic development via a thermooptical technique.

Polarized optical micrographs of neat and plasticized PLA samples after melting and cooling to the isothermal crystallization of $120^{\circ} \mathrm{C}$ are shown in Figure 5. The neat PLA forms a well-defined Maltese cross pattern of spherulites with a average diameter of about $20 \mu \mathrm{m}$ (Figure 5a). The spherulite size seems to increase as a result of blending PLA with EPO (Figure 5b). This confirms that the crystallization behaviors of PLA are hindered with the existence of EPO, which is in a good agreement with the DSC results. The presence of GP tends to decrease the PLA spherulite size (Figures $\mathbf{5 c}$ and $\mathbf{5 d}$ ). The results indicate that the GP can act as a nucleating agent, where a high number of heterogenous nuclei lead to smaller spherulites. This result is in good agreement with DSC thermograms in the previous discussion.

The Young's modulus and tensile strength at yield of the PLA and PLA/EPO samples are plotted in Figures 6. The incorporation of EPO decreases the Young's modulus of the PLA as the plasticizing effect of the EPO. It can also be seen that both the Young's modulus and the
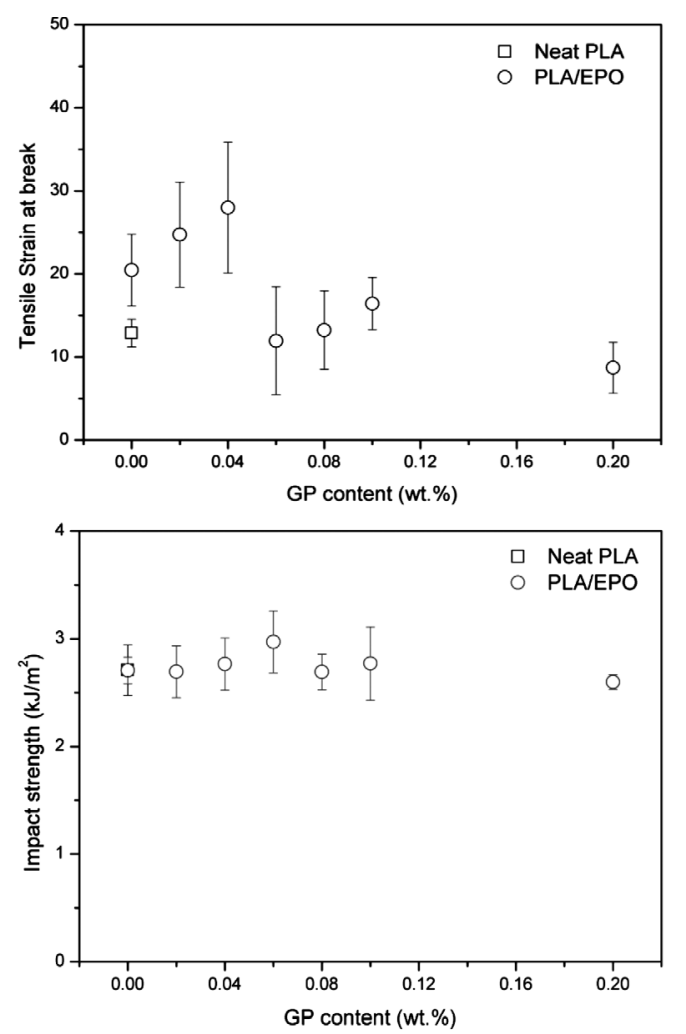

Figure 7: Tensile strain at break (left) and impact strength of neat PLA and PLA/ESO blends with and without GP 
tensile-strength evaluation does not well define the dependence of GP loading, and seems not to be significantly affected by the GP addition. From the tensile results, the reinforcement effect of the GP on the PLA/EPO blend is ambiguous. This could be because of poor nanoparticle/matrix interfacial adhesion, preferential dispersion of the GP in the EPO rather than in the PLA and/or GP loading. Due to its ability to crystallize, the mechanical properties of PLA not only depend on the reinforcement of the nanoparticle, but also its crystallinity and spherulite size. The microscopy analysis reveals the reduction in the size of spherulites with the incorporation of GP. A smaller spherulite generally causes a tensile strength. ${ }^{21}$ On the other hand, a higher crystallinity of PLA in PLA/EPO/GP0.2 results in a small increase in the Young's modulus. It is the crystalline phase rather than the amorphous phase that is stronger and more difficult to deform. C. Sriprachuabwong et al. ${ }^{13}$ reported that the Young's modulus and tensile strength of the PLA/EPO blend decrease linearly with the increasing GP loading (ranged from $0.2 w / \%$ to $0.8 w / \%)$, attributed to the weak interface adhesion between the GP and PLA. B. W. Chieng et al. ${ }^{22}$ also found a similar result of the reduction in tensile strength on hybrid plasticized PLA/xGnP nanocomposites. Although the Young's modulus of the hybrid plasticized PLA with $0.1 \mathrm{w} / \%$ loading was about $10 \%$ greater than that of the hybrid plasticized PLA, it decreased significantly with increasing $\mathrm{xGnP}$ loading (up to $1 \mathrm{w} / \%$ ).

As is well known, the plasticization of EPO normally gives high flexibility. As expected, the elongation at break of the PLA is enhanced with the addition of EPO, as shown in Figure 7 (left), and the large standard deviation should be noted. In addition, elongation at break increases with increasing GP loading up to $0.04 \mathrm{w} / \%$, then decreases as the GP loading increases further to $0.2 w / \%$. The increase in the elongation at break of PLA/EPO at lower GP loading could be explained by the reduction of PLA spherulite size. As is well known, the spherulitic structure occurs by the stack of folded chain lamellar crystal. The connections between lamellar crystals are called tie-molecules. The smaller spherulite size leads to a larger number of tie-molecules, resulting in an increase of the flexibility and impact strength..$^{23}$ On the other hand, when the GP loading is increased, the spherulite size is less effective on the improvement of flexibility. This result agrees with Chieng et al., reports which stated that the decrease of elongation at break with increasing filler loading may be associated with a large aspect ratio of filler and the interfacial adhesion between the filler and the polymer matrix. ${ }^{8}$ This restricts the effectiveness of the stress transfer between the polymer matrix and the filler. Figure 7 (right) presents the impact strength of PLA/EPO/ GP nanocomposites. As seen, the effect of GP nanoparticles is not pronounced in the impact-strength improvement. The presence of GP retains the impact strength of the PLA/EPO over the range of GP loading, even the reduction of the elongation at the break of PLA/EPO at a high GP loading is found. This could be due to the differences in the stain rate of two testing methods, as related to different applications.

From the above discussion, we can conclude that the mechanical properties of the PLA/EPO blend is
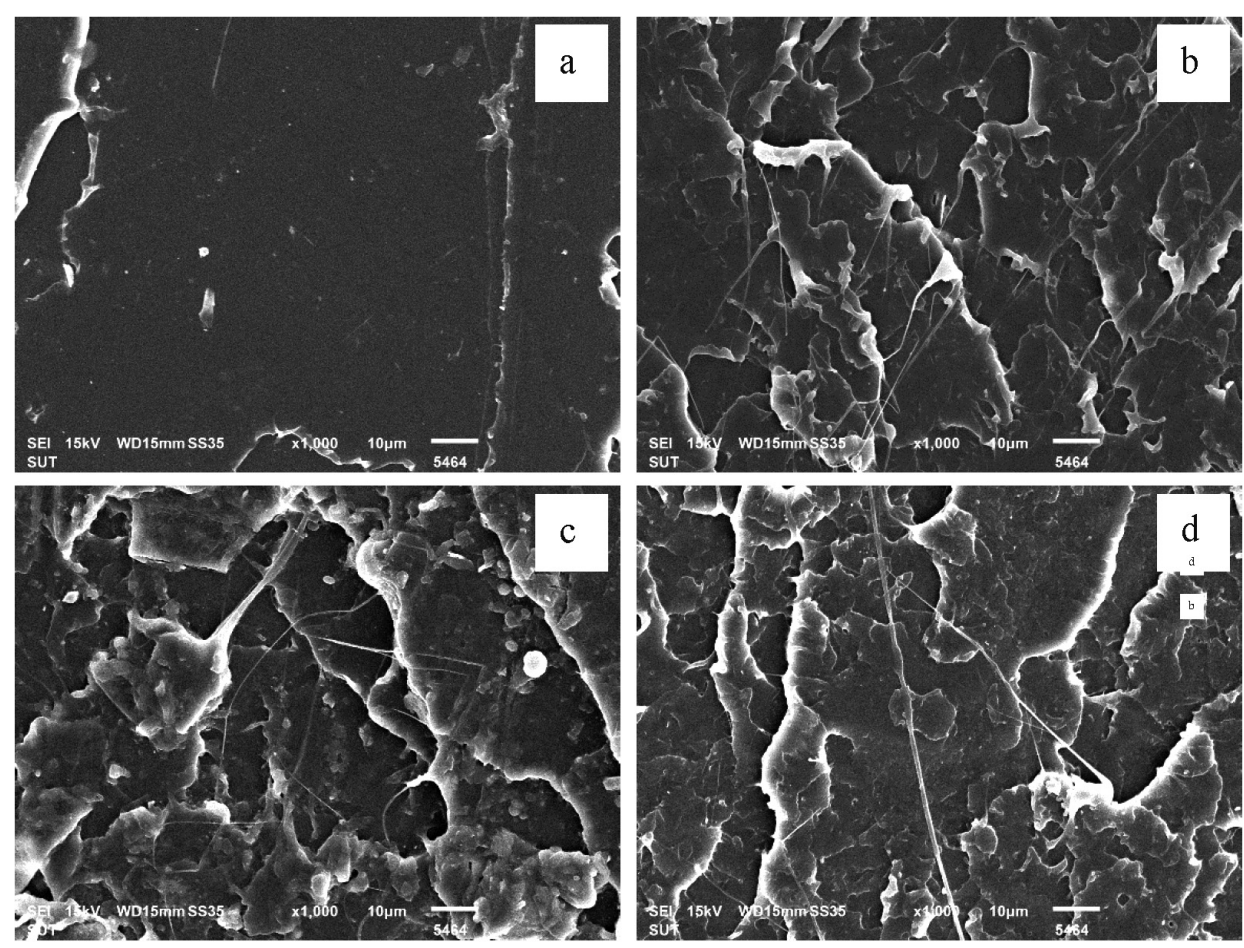

Figure 8: SEM micrographs of fractured surface of: a) Neat PLA, b) PLA/EPO, c) PLA/EPO/GP0.02 w/\%, d) PLA/EPO/GP0.10 w/\% 
determined not only by nanoparticle/matrix interfacial adhesion and nanoparticle loading, but also the main morphological parameters, such as the degree of crystallinity and the spherulite size. The interplay between these factors cannot always be separated.

The SEM micrographs revealed a rather brittle fracture of neat PLA without any visible plastic deformation on the smooth fractured surface of the impact sample, as shown in Figure 8a). The addition of EPO ( Figure 8b) is brought into relative rough fractured surface with a fibrous structure, which is evidence of the ductile fractures. ${ }^{5}$ In PLA/EPO/GP nanocomposites, the GP nanoparticles on the fractured surface are not easily distinguishable, even from high magnification due to the surface sample instability when a large magnification is attempted. However, the SEM micrographs of the impact fractured surface of the PLA/EPO/GP nanocomposites (Figure $\mathbf{8 c}$ and $\mathbf{8 d}$ ) retain a fibrous structure on the rough fractured surface. From this we can deduce that the toughness improvement of the PLA is contributed by the plasticization of the EPO.

\section{CONCLUSIONS}

This work presents the influence of GP nanoparticles on the morphology of PLA and the mechanical properties of the PLA/EPO blend. The crystallization of the PLA in the PLA/EPO/GP system is influenced by a competition effect of the EPO as plasticizer and GP as the nucleating agent. In neat PLA, GP induces a higher degree of crystallinity of PLA, along with the lower cold crystallization, but its effectiveness is less pronounced in PLA/EPO. A drop in the ability to nucleate the GP in the PLA/EPO blend could be due to the preferred dispersion in the EPO phase. In addition, the resulting tensile properties of PLA/EPO filled with GP is a result of an efficiency of stress transfer and the morphology of the PLA. As of interest, with higher crystallinity obtained in the presence of GP, a small increase in the Young's modulus and tensile strength of PLA/EPO can be attained.

\section{Acknowledgment}

The authors would like to thank the Faculty of Engineering and Technology, King Mongkut's University of Technology North Bangkok, Thailand, for experimental support of this work. The authors also thank the Haydale Technologies (Thailand) Company Limited for the supply of the graphene.

\section{REFERENCES}

${ }^{1}$ J. Kolařík, A. Pegoretti, Indentation creep of heterogeneous blends of poly(ethylene terephthalate)/impact modifier, Polymer Testing, 23 (2004) 1, 113-121, doi:10.1016/S0142-9418(03)00069-2
${ }^{2}$ L. Jiang, M. P. Wolcott, J. Zhang, Study of biodegradable polylactide/poly(butylenes adipate-co-terephthalate) blends, Biomacromolecules, 7 (2006) 1, 199-207, doi:10.1021/bm050581q

${ }^{3}$ B. Suksut, C. Deeprasertkul, Effect of nucleating agents on physical properties of poly(lactic acid) and its blend with natural rubber, Journal of Polymers and the Environment, 19 (2011) 1, 288-296, doi:10.1007/s10924-010-0278-9

${ }^{4}$ Z. Kulinski, E. Piorkowska, K. Gadzinowska, M. Stasiak, Plasticization of poly(L-lactide) withpoly (propyleneglycol), Biomacromolecules, 7 (2006) 7, 2128-2135, doi:10.1021/bm060089m

${ }^{5}$ K. Sungsanit, N. Kao, S. N. Bhattacharya, Properties of linear poly(lactic acid)/polyethylene glycol blends, Polymer Engineering and Science, 52 (2012) 1, 108-116, doi:10.1002/pen.22052

${ }^{6}$ F. Ali, Y. W. Chang, S. C. Kang, J. Y. Yoon, Thermal, mechanical and rheological properties of poly(lactic acid)/epoxidized soybean oil blends, Polymer Bulletin, 62 (2009) 1, 91-98, doi:1007/s00289008-1012-9

${ }^{7}$ E. A. J. Al-Mulla, W. Md. Z. W. Yunus, N. A. B. Ibrahim, M. Z. A. Rahman, Properties of epoxidized palm oil plasticized polytlactic acid, Journal of Materials Science, 45 (2010) 7, 1942-1946, doi: 10.1007/s10853-009-4185-1

${ }^{8}$ B. W. Chieng, N. A. Ibrahim, W. M. Z. W. Yunus, M. Z. Hussein, V. S. G. Silverajah, Graphene nanoplatelets as novel reinforcement filler in poly(lactic acid)/epoxidized palm oil green nanocomposites: mechanical properties, International Journal of Molecular Sciences, 13. (2012) 9, 10920-34, doi:10.3390/ijms 130910920

${ }^{9}$ E. A. J. Al-Mulla, A. H. Suhail, S. A. Aowda, New biopolymer nanocomposites based on epoxidized soybean oil plasticized poly(lactic acid)/fatty nitrogen compounds modified clay: preparation and characterization, Industrial Crops and Products, 33 (2011) 1, 23-29, doi:10.1016/j.indcrop.2010.07.022

${ }^{10} \mathrm{~S}$. Gumus, G. Ozkoc, A. Aytac, Plasticized and unplasticized PLA/organoclay nanocomposites: short- and long-term thermal properties, morphology, and nonisothermal crystallization behavior, Journal of Applied Polymer Science, 123 (2012) 5, 2837-2848, doi:10.1002/app.34841

${ }^{11}$ X. Meng, V. Bocharova, H. Tekinalp, S. Cheng, A. Kisliuk, A. P. Sokolov, V. Kunc, W. H. Peter, S. Ozcan, Toughening of nanocelluose/PLA composites via bio-epoxy interaction: mechanistic study, Materieals \& Design, 139 (2018) 5, 188-197, doi:10.1016/ j.matdes.2017.11.012

${ }^{12}$ Y. Arfat, J. Ahmed, M. Ejaz, M. Mullah, Polylactide/graphene oxide nanosheets/clove essential oil composite films for potential food packaging applications, International Journal of Biological Macromolecules, 107 (2018), 194-203, doi:10.1016/j.ijbiomac.2017. 08.156

${ }^{13}$ C. Sriprachuabwong, S. Duangsripat, K. Sajjaanantakul, A. Wisitsoraat, A. Tuantranont, Electrolytically exfoliated graphenepolylactide-based bioplastic with high elastic performance, Journal of Applied Polymer Science, 132 (2014) 6, doi:10.1002/app.41439

${ }^{14}$ V. S. G. Silverajah, N. A. Ibrahim, W. M. Z. W. Yunus, H. A. Hassan, C. B. Woei, A comparative study on the mechanical, thermal and morphological characterization of poly(lactic acid)/epoxidized palm oil blend, International Journal of Molecular Sciences, 13 (2012), 5878-5898, doi:10.3390/ijms 13055878

${ }^{15}$ F. Tuinstra, J. L. Koenig, Raman spectrum of graphite, The Journal of Chemical Physics, 53 (1970) 3, 1126-1130, doi:10.1063/ 1.1674108

${ }^{16}$ A. C. Ferrari, Raman spectroscopy of graphene and graphite: disorder, electron-phonon coupling, doping and nonadiabatic effects, Solid State Communications, 143 (2007) 1-2, 47-57, doi:10.1016/ j.ssc.2007.03.052

${ }^{17}$ Y. Gao, O. T. Picot, E. Bilotti, T. Peijs, Influence of filler size on the properties of poly(lactic acid) (PLA)/graphene nanoplatelet (GNP) nanocomposites, European Polymer Journal, 86 (2017), 117-131, doi:10.1016/j.eurpolymj.2016.10.045 


\section{B. SUKSUT, S. DUANGSRIPAT: EFFECT OF GRAPHENE ON THE PROPERTIES OF EPOXIDIZED-PALM-OIL ...}

${ }^{18}$ A. M. Pinto, J. Cabrail, D. A. P. Tanada, A. M. Mendes, F. D. Magalhães, Effect of incorporation of graphene oxide and graphene nanoplatelets on mechanical and gas permeability properties of poly(lactic acid) films, Polymer International, 62 (2013) 1, 33-40, doi:10.1002/pi.4290

${ }^{19}$ S. Kim, W. H. Jo, J. Kim, S. H. Lim, C. R. Choe, The effect of crystalline morphology of poly (butylene terephthalate) phases on toughening of poly(butylene terephthalate)/epoxy blends, Journal of Materials Science, 34 (1999) 1, 161-168, doi:10.1023/ A: 1004410901853

${ }^{20}$ M. Mucha, Z. Królikowski, Application of DSC to study crystallization kinetics of polypropylene containing fillers, Journal of Thermal Analysis and Calorimetry, 74 (2003) 2, 549-557, doi:10.1023/B:JTAN.0000005193.66789.ea
${ }^{21}$ R. Popli, L. Mandelkern, Influence of structural and morphological factors on the mechanical properties of the polyethylenes, Journal of Polymer Science Part B Polymer Physics, 25 (1987) 3, 441-483, doi:10.1002/polb.1987.090250301

${ }^{22}$ B. W. Chieng, N. A. Ibrahim, W. M. Z. W. Yunus, M. Z. Hussein, Y. Y. Then, Y. Y. Loo, Reinforcement of graphene nanoplatelets on plasticized poly(lactic acid) nanocomposites: mechanical, thermal, morphology, and antibacterial properties, Journal of Applied Polymer Science, 132 (2015) 11, doi:10.1002/APP.41652

${ }^{23}$ T. Xu, J. Yu, Z. Jin, Effects of crystalline morphology on the impact behavior of polypropylene, Materials and Design, 22 (2001) 1, 27-31, doi:10.1016/S0261-3069(00)00033-9 